\title{
Sunshine and Temperature Dependent Models for Estimating Global Solar Radiation Across the Guinea Savannah Climatic Zone of Nigeria
}

\author{
Davidson Odafe Akpootu ${ }^{1,}$, , Bello Idrith Tijjani ${ }^{2}$, Usman Mohammed Gana ${ }^{2}$ \\ ${ }^{1}$ Department of Physics, Usmanu Danfodiyo University, Sokoto, Nigeria \\ ${ }^{2}$ Department of Physics, Bayero University, Kano, Nigeria
}

Email address:

davidson.odafe $a$ udusok.edu.ng (D. O. Akpootu), profdon03 ayahoo.com (D. O. Akpootu)

${ }^{*}$ Corresponding author

To cite this article:

Davidson Odafe Akpootu, Bello Idrith Tijjani, Usman Mohammed Gana. Sunshine and Temperature Dependent Models for Estimating Global Solar Radiation Across the Guinea Savannah Climatic Zone of Nigeria. American Journal of Physics and Applications. Vol. 7, No. 5, 2019, pp. 125-135. doi: 10.11648/j.ajpa.20190705.15

Received: August 26, 2019; Accepted: September 24, 2019; Published: October 30, 2019

\begin{abstract}
This study investigates the most accurate sunshine and temperature dependent models for estimating global solar radiation over Makurdi and Ibadan situated in the Guinea savannah of Nigeria by comparing nine (9) different existing sunshine dependent models. The study also proposed two temperature dependent models that took the form of quadratic logarithmic and quadratic exponential and were compared to three existing temperature dependent models (Chen, Hargreaves and Samani (HS) and Garcia). The measured monthly average daily global solar radiation, sunshine hours, maximum and minimum temperature meteorological parameters during the period of thirty one (1980-2010) years was utilized and the accuracy of the sunshine and temperature dependent models to ascertain the most suitable models in each location were tested using seven various statistical validation indicators of coefficient of determination $\left(\mathrm{R}^{2}\right)$, Mean Bias Error (MBE), Root Mean Square Error (RMSE), Mean Percentage Error (MPE), t-test, Nash-Sutcliffe Equation (NSE) and Index of Agreement (IA). The results revealed that the exponent sunshine dependent model proposed by Bakirci and the linear exponential sunshine dependent model proposed by Bakirci were found more accurate for estimating global solar radiation in Makurdi and Ibadan respectively. The proposed quadratic logarithmic and quadratic exponential temperature dependent models were found more suitable for estimating global solar radiation in Makurdi and Ibadan respectively. These recommended models can be found appropriate, if properly calibrated in regions with similar climatic information. The HS temperature dependent model evaluated in this study for Ibadan was compared with those available in literatures and was found more suitable. Furthermore, the most suitable sunshine dependent model was found more suitable for global solar radiation estimation when compared to the most suitable temperature dependent model in each of the studied locations and this was testified from the figures of the comparison between the measured and estimated sunshine and temperature dependent models as the sunshine dependent models depicts the best fitting with the measured global solar radiation data.
\end{abstract}

Keywords: Global Solar Radiation, Guinea Savannah Climatic Zone, Sunshine and Temperature Dependent Models, Statistical Validation Indicators, Meteorological Parameters

\section{Introduction}

Solar radiation data has been considered as an essential requirement to conduct feasibility studies for solar energy systems. A reasonable estimate of global solar radiation is important for most of the solar energy applications at any place. Knowledge of the availability of global solar radiation data is of basic importance in utilizing solar energy economically and efficiently. Technology for measuring solar radiation is costly and has instrumental hazards [1]. Thus, alternative methods for estimating these data are required. One of these methods is the use of empirical models. Accurate modeling depends on the quality and quantity of the measured data used, and is a good tool for generating solar radiation at locations where measured data are not available [2].

The widely used correlations for estimating solar radiation 
are mainly based on sunshine duration and air temperature. In fact, the models estimating solar radiation from sunshine duration are generally more accurate than those involving other meteorological observations [3-6]. On a contrary, in the study carried out by Ogolo [7], he found that the temperature dependent models are more suitable for estimating global solar radiation in the sahelian and coastal region of Nigeria, except in the Midland and Guinea savannah where the sunshine dependent models are more suitable. The sunshine duration is not as readily available as air temperature data at standard meteorological stations [8-9]. So, it is meaningful to elaborate models that estimate solar radiation based on air temperature as an alternative [10].

Several models have been proposed to estimate global solar radiation. Ångström [11] was the first scientist known to suggest a simple linear relationship to estimate global solar radiation. Page [12] presents a linear regression model used in correlating the global solar radiation data with relative sunshine duration, which is a modified Ångström type model. El-Sebaii and Trabea [13] present and analyzed the global solar radiation and sunshine duration data recorded at five cities which represent the various weather conditions of Egypt. The data covered a period of three years (1990-1992) while for Tanta (1986-1988). New constants for the first, second and third order Ångström type correlations were also developed which according to them may be used for estimating global solar radiation at any location of Egypt. According to them, statistical comparisons between measured and estimated global solar radiation indicated that the second and third order Ångström type correlations do not improve the accuracy of estimation of global solar radiation. Therefore, first order or linear correlations between the monthly average daily clearness index and the relative possible sunshine duration for the selected locations and also for all Egypt was proposed. Isikwue et al. [14] proposes the coefficients for Ångström-Prescott type of model for the estimation of global solar radiation in Makurdi, Nigeria using relative sunshine duration alongside the measured global solar radiation data obtained from Air force Based Makurdi, Nigeria, between the periods (2001-2010). The model constants "a" and "b" obtained in their investigation for Makurdi are 0.138 and 0.488 respectively. Gadiwala et al. [15] estimates global solar radiation for five different stations in Pakistan using different sunshine based models. The mean monthly sunshine hour and mean monthly solar radiation were obtained from Computerized Data Processing Centre, Karachi for the period 1961-2009. According to them, the Ångström model provides the best estimation of global solar radiation. Olatona and Adeleke [16] developed some simple empirical models for the prediction of monthly mean daily solar radiation on a horizontal surface for Ibadan from sunshine hours and minimum and maximum temperatures data obtained from International Institute of Tropical Agriculture (IITA) Meteorological station at Ibadan, the data obtained covered a period of twenty years (1992-2011). Their results showed that the sunshine hour has lower mean errors than those based on minimum and maximum temperature which consistently produced an overestimation.

The purpose of this study is to (i) compare nine different sunshine dependent models to ascertain the most suitable model for estimating global solar radiation in Makurdi and Ibadan (ii) to develop new temperature dependent models for estimating global solar radiation in each of the studied areas; and (iii) compare the most suitable sunshine and temperature dependent model with a view to find out which is more suitable in the Guinea savannah climatic zone of Nigeria using meteorological parameters of monthly average daily global solar radiation, sunshine hours, maximum and minimum temperature during the period of thirty one (1980-2010) years..

\section{Methodology}

\subsection{Acquisition of Data}

It was mentioned according to the World Meteorological Organization [17] and Ojo and Adeyemi [18] that to ensure the optimal climate modelling, data series should be a minimum of thirty years long. Based on this, the measured monthly average daily global solar radiation, maximum and minimum temperature meteorological data during the period of thirty one years (1980-2010) was used in this study. The meteorological data were obtained from the Nigerian Meteorological Agency (NIMET), Oshodi, Lagos, Nigeria. Twenty five (25) (19802004) years data was used for developing the empirical models while six (6) years (2005-2010) data was used for validation of the models. According to Olaniran [19] Nigeria is classified into four climatic zones; these are the Coastal zone, Guinea savannah zone, Midland zone and the Sahelian zone. The locations within the Guinea savannah zone considered in this study are shown in Figure 1.

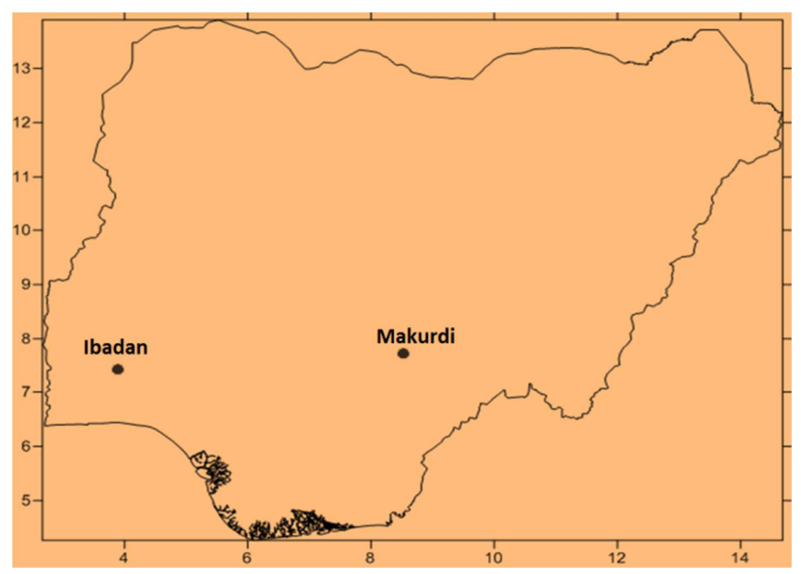

Figure 1. Location of the studied regions in Nigeria.

\subsection{Regression Analysis}

The monthly average daily extraterrestrial radiation on a horizontal surface $\left(H_{o}\right)$ in $\mathrm{MJ} / \mathrm{m}^{2} /$ day can be calculated for days giving average of each month from the following equation [2021]: 


$$
H_{o}=\left(\frac{24}{\pi}\right) I_{s c}\left[1+0.033 \cos \left(\frac{360 n}{365}\right)\right]\left[\cos \varphi \cos \delta \sin \omega_{s}+\left(\frac{2 \pi \omega_{s}}{360}\right) \sin \varphi \sin \delta\right]
$$

where $I_{s c}$ is the solar constant $\left(=1367 \mathrm{Wm}^{-2}\right), \varphi$ is the latitude of the site, $\delta$ is the solar declination and $\omega_{s}$ is the mean sunrise hour angle for the given month and $n$ is the number of days of the year starting from $1^{\text {st }}$ of January to $31^{\text {st }}$ of December.

The solar declination, $\delta$ and the mean sunrise hour angle, $\omega_{s}$ can be calculated using the following equation [20-21]:

$$
\begin{gathered}
\delta=23.45 \sin \left\{360\left(\frac{284+n}{365}\right)\right\} \\
\omega_{s}=\cos ^{-1}(-\tan \varphi \tan \delta)
\end{gathered}
$$

For a given month, the maximum possible sunshine duration (monthly average day length $\left(S_{o}\right)$ ) in hours can be computed [20-21] by

$$
S_{o}=\frac{2}{15} \omega_{S}
$$

The clearness index $\left(K_{T}\right)$ is defined as the ratio of the observed/measured horizontal terrestrial solar radiation $H$, to the calculated/predicted/estimated horizontal extraterrestrial solar radiation $H_{o}[22]$.

$$
K_{T}=\frac{H}{H_{o}}
$$

where $H$ is the monthly average daily global solar radiation on a horizontal surface $\left(\mathrm{MJ} / \mathrm{m}^{2} /\right.$ day). In this study, $H_{o}$ and $S_{o}$ were computed for each month using equations (1) and (4) respectively.

Tables 1 and 2 shows the existing sunshine and temperature dependent models obtained from the literature that were evaluated in this study to determine their respective empirical coefficients which was used for the validation using seven different statistical indicators. In table 1, nine (9) existing sunshine dependent models were utilized while in Table 2; three (3) existing temperature dependent models were utilized. In this study, two new temperature dependent models (Table 3 ) were proposed and compared with the three existing models. Attempt were made to propose new

\begin{tabular}{|c|c|c|c|}
\hline Model No. & Model Type & Regression equation & Source \\
\hline 1 & Linear (Ångström) & $\frac{H}{H_{o}}=a+b\left(\frac{S}{S_{o}}\right)$ & Angstom [11] and Prescott [23] \\
\hline 2 & Quadratic & $\frac{H}{H_{0}}=a+b\left(\frac{S}{S_{0}}\right)+c\left(\frac{S}{s_{0}}\right)^{2}$ & Ogelma et al.[24] \\
\hline 3 & Cubic & $\frac{H}{H_{0}}=a+b\left(\frac{s}{s_{0}}\right)+c\left(\frac{s}{s_{0}}\right)^{2}+d\left(\frac{s}{s_{0}}\right)^{3}$ & Samuel [25] \\
\hline 4 & $\begin{array}{l}\text { Linear } \\
\text { Logarithmic }\end{array}$ & $\frac{H}{H_{0}}=a+b\left(\frac{S}{s_{0}}\right)+c \ln \left(\frac{S}{s_{0}}\right)$ & Newland [26] \\
\hline 6 & $\begin{array}{l}\text { Linear } \\
\text { Exponential }\end{array}$ & $\frac{H}{H_{o}}=a+b\left(\frac{s}{s_{o}}\right)+c \exp \left(\frac{s}{s_{0}}\right)$ & KadirBakirci [28] \\
\hline 7 & Exponential & $\frac{H}{H_{o}}=a+b \exp \left(\frac{S}{S_{0}}\right)$ & Almorox and Hontoria [29] \\
\hline 8 & Linear (Louche) & $\frac{H}{H_{0}}=a+b\left(\frac{S}{S_{n h}}\right)$ & Louche et al. [30] \\
\hline 9 & Exponent & $\frac{H}{H_{0}}=a\left(\frac{S}{S_{0}}\right)^{b}$ & KadirBakirci [28] \\
\hline
\end{tabular}
sunshine dependent models; however, not found suitable for estimating global solar radiation when compared with the existing sunshine based models.

Table 1. Sunshine dependent models proposed in the literature used in this study.

Table 2. Temperature based models proposed in the literature used in this study.

\begin{tabular}{llll}
\hline Model No. & Model Type & Regression equation & Source \\
\hline 1 & Logarithmic & $\frac{H}{H_{0}}=a_{2}+b_{2} \ln \Delta T$ & Chen et al. [31] \\
2 & Linear exponent & $\frac{H}{H_{0}}=a_{3}+b_{3} \Delta T^{0.5}$ & Hargreaves and Samani [32] \\
3 & Linear & $\frac{H}{H_{0}}=a_{4}+b_{4}\left(\frac{\Delta T}{S_{0}}\right)$ & Garcia [33] \\
\hline
\end{tabular}

where $H, H_{0}$ and $S_{0}$ are as previously defined. $\Delta T$ is the difference between the monthly average daily maximum and minimum temperature i.e., $T_{\max }-T_{\min }$.

The constants $a_{2,}, a_{3}, a_{4}, b_{2}, b_{3}$ and $b_{4}$ in Table 1 are empirical coefficients determined by regression analysis and the other terms are the model correlated parameters. The models are basically the three widely used temperature dependent models and has been found suitable in all climatic conditions. The five proposed temperature dependent models in this study are given in Table 2.

Table 3. Temperature based regression model proposed in this study.

\begin{tabular}{lll}
\hline Model No. & Model Type & Regression equation \\
\hline 1 & Quadratic logarithmic & $\frac{H}{H_{o}}=a+(\Delta T)+c(\Delta T)^{2}+d \ln (\Delta T)$ \\
2 & Quadratic & $\frac{H}{H_{o}}=a+b(\Delta T)+c(\Delta T)^{2}+\operatorname{dexp}(\Delta T)$ \\
\hline
\end{tabular}


The models in Table 2 are proposed for this study in form of mathematical equations that relate the clearness index as the dependent variable and temperature as the independent variables. The proposed temperature dependent models are based on the modification of the existing models. The essence of modification is to find out if it improves the accuracy of the existing models.

The accuracy or validation of the estimated values was statistically tested by computing the MBE, RMSE, MPE, ttest, NSE and the IA, similarly, $R^{2}$ was determined for each of the models. The expressions for the MBE, RMSE and MPE as stated according to El-Sebaii and Trabea [13] are given as follows.

$$
\begin{aligned}
M B E & =\frac{1}{n} \sum_{i=1}^{n}\left(H_{i, c a l}-H_{i, \text { mea }}\right) \\
R M S E & =\left[\frac{1}{n} \sum_{i=1}^{n}\left(H_{i, \text { cal }}-H_{i, m e a}\right)^{2}\right]^{\frac{1}{2}} \\
M P E & =\frac{1}{n} \sum_{i=1}^{n}\left(\frac{H_{i, \text { mea }}-H_{i, c a l}}{H_{i, \text { mea }}}\right) * 100
\end{aligned}
$$

The t-test defined by student [34] in one of the tests for mean values, the random variable $t$ with $n-1$ degrees of freedom may be written as follows.

$$
t=\left[\frac{(n-1)(M B E)^{2}}{(R M S E)^{2}-(M B E)^{2}}\right]^{\frac{1}{2}}
$$

The study site was statistically tested at the $(1-\alpha)$ confidence levels of significance of $95 \%$ and $99 \%$. For the critical t-value, i.e., at $\alpha$ level of significance and degree of freedom, the calculated t-value must be less than the critical value $\left(t_{\text {critical }}=2.20, d f=11, p<0.05\right)$ for $95 \%$ and $\left(t_{\text {critical }}=3.12, d f=11, p<0.01\right)$ for $99 \%$.

The Nash-Sutcliffe equation (NSE) is given by the expression

$$
N S E=1-\frac{\sum_{1}^{n}\left(H_{i, m e a}-H_{i, c a l}\right)^{2}}{\sum_{1}^{n}\left(H_{i, m e a}-\bar{H}_{i, m e a s}\right)^{2}}
$$

The Index of Agreement (IA) is given as

$$
I A=1-\frac{\sum_{i=1}^{n}\left(H_{i, c a l}-H_{i, m e a}\right)^{2}}{\sum_{i=1}^{n}\left(\left|H_{i, c a l}-\bar{H}_{i, m e a}\right|+\left|H_{i, m e a}-\bar{H}_{i, \text { mea }}\right|\right)^{2}}
$$

From equations (6)-(11) $H_{i, \text { mea }}, H_{i, c a l}$ and $n$ are

respectively the $i^{\text {th }}$ measured and $i^{\text {th }}$ calculated values of monthly averaged global solar radiation and the total number of observations, also $\bar{H}_{i, \text { mea }}$ is the mean measured global radiation.

Chen et al. [31] have recommended that a zero value for MBE is ideal and a low RMSE and MPE are desirable. The smaller the value of the MBE, MPE and RMSE the better is the model's performance, a positive MPE and MBE values provide the averages amount of overestimation in the calculated values, while the negative values gives underestimation. The percentage error between $-10 \%$ and $+10 \%$ is considered acceptable [35]. The smaller the value of $t$ the better is the performance. High value of $\mathrm{R}^{2}$, NSE and IA are desirable. The MBE and the RMSE are in $\mathrm{MJm}^{-2} \mathrm{day}^{-1}$, while $\mathrm{R}^{2}$, MPE, NSE and IA are in percentage (\%), the t-test is non dimensional.

\section{Results and Discussion}

\subsection{Sunshine and Temperature Dependent Models}

\subsubsection{Sunshine Based Models for Makurdi}

The empirical sunshine dependent models for Makurdi obtained through regression techniques based on Table 1 are

$$
\begin{gathered}
\frac{H}{H_{0}}=0.156+0.713 \frac{S}{S_{0}} \\
\frac{H}{H_{0}}=0.030+1.23 \frac{S}{S_{0}}-0.506\left(\frac{S}{S_{0}}\right)^{2} \\
\frac{H}{H_{0}}=0.63-2.37 \frac{S}{S_{0}}+6.5\left(\frac{S}{S_{0}}\right)^{2}-4.5\left(\frac{S}{S_{0}}\right)^{3} \\
\frac{H}{H_{0}}=0.578+0.218 \frac{S}{S_{0}}+0.246 \ln \left(\frac{S}{S_{0}}\right) \\
\frac{H}{H_{0}}=0.763+0.353 \ln \left(\frac{S}{S_{0}}\right) \\
\frac{H}{H_{0}}=-0.192+0.426 \exp \left(\frac{S}{S_{0}}\right) \\
\frac{H}{H_{0}}=0.156+0.816 \frac{S}{S n h} \\
\frac{H}{H_{0}}=0.833\left(\frac{S}{S_{0}}\right)^{0.697}
\end{gathered}
$$

Table 4. Statistical analysis of the sunshine dependent models for Makurdi.

\begin{tabular}{lllllll}
\hline Models & $\mathbf{R}^{2}$ & MBE & RMSE & MPE & t & NSE \\
\hline Eqn.12 & 90.4 & 0.0032 & 0.694 & -0.0778 & 0.0155 & 95.3551 \\
Eqn.13 & 90.8 & 0.0937 & 0.6925 & -0.5341 & 0.4528 & 95.3746 \\
Eqn.14 & 91.0 & -0.2461 & 0.7224 & 1.2500 & 1.2016 & 98.8315 \\
Eqn.15 & 90.8 & 0.0183 & 0.6855 & -0.1328 & 0.0887 & 9.1299 \\
Eqn.16 & 90.7 & 0.0270 & 0.6899 & -0.1722 & 9676 \\
Eqn.17 & 90.8 & 0.0741 & 0.6894 & -0.4287 & 0.3584 & 95.4687 \\
Eqn.18 & 89.6 & 0.0118 & 0.7187 & -0.1495 & 0.0545 & 95.4170 \\
Eqn.19 & 90.4 & 0.0095 & 0.6948 & -0.1116 & 0.0454 & 95.4170 \\
Eqn.20 & 91.4 & -0.0024 & 0.6866 & -0.0308 & 9.0117 & 95.3443 \\
\hline
\end{tabular}


Table 5. Ranking of the evaluated sunshine dependent models for Makurdi.

\begin{tabular}{|c|c|c|c|c|c|c|c|c|}
\hline Models & $\mathbf{R}^{2}$ & MBE & RMSE & MPE & $t$ & NSE & IA & Total Rank \\
\hline Eqn.12 & 5 & 2 & 6 & 2 & 2 & 6 & 6 & 29 \\
\hline Eqn.13 & 3 & 8 & 5 & 8 & 8 & 5 & 2 & 39 \\
\hline Eqn.14 & 2 & 9 & 9 & 9 & 9 & 8 & 9 & 55 \\
\hline Eqn.16 & 4 & 6 & 4 & 6 & 6 & 4 & 4 & 34 \\
\hline Eqn. 17 & 3 & 7 & 3 & 7 & 7 & 3 & 1 & 31 \\
\hline Eqn. 18 & 6 & 4 & 8 & 5 & 4 & 3 & 8 & 38 \\
\hline Eqn. 20 & 1 & 1 & 2 & 1 & 1 & 2 & 5 & 13 \\
\hline
\end{tabular}

Tables 4 and 5 summarizes the different statistical validation indicators utilized in this study and the ranking of the sunshine dependent models for Makurdi. Based on the $\mathrm{R}^{2}$ the model, equation 20 (exponent) sunshine dependent model has the highest value of $91.4 \%$; the model also has the lowest MBE, MPE and t-test values with underestimation of $0.0024 \mathrm{MJm}^{-}$ ${ }^{2} \mathrm{day}^{-1}$ and $0.0308 \%$ in their estimated values and 0.0117 respectively. The model equation 15 (linear logarithmic) has the lowest and highest values of RMSE and NSE with $0.6855 \mathrm{MJm}^{-}$ ${ }^{2}$ day $^{-1}$ and $95.4687 \%$ respectively. The model equation 17 (linear exponential) has the highest IA value of $98.8777 \%$. The result of the sunshine dependent models for Makurdi show that regardless of the overestimation and underestimation exhibited in their estimated values they are all within the acceptable range $(M P E \leq \pm 10 \%)$. Similarly, the calculated t-test values are less than the critical t-test values for all the examined models; therefore the t-test analysis shows that all the studied models are significant at $95 \%$ and $99 \%$ confidence levels.

The total ranks acquired by the various sunshine dependent models (Table 5) were in the range 13 to 55. The overall results for Makurdi; revealed that the exponent sunshine dependent model given in equation 20 as proposed by Bakirci [28] was found more accurate for estimating global solar radiation in this location as compared to other evaluated sunshine dependent models.

The $1^{\text {st }}$ order evaluated Ångström type model results obtained for Makurdi in this study were compared to that carried out by Isikwue et al. [14]. The model equation with its empirical constants is given in equation 12 while the empirical constants given by Isikwue et al. [14] are 0.138 and 0.488 . In this study, $\mathrm{R}^{2}$ where compared to that of Isikwue et al. [14] as that is the only statistical test performed by them. In this study $\mathrm{R}^{2}$ is $90.4 \%$ while in their case $\mathrm{R}^{2}$ is $79.5 \%$. Thus, this is evident that the evaluated Ångström type model in this study performs better than their model based on the statistical test result. However, the exponent sunshine dependent model given in equation 20 as proposed by Bakirci [28] is reported as the best and therefore most suitable for estimating global solar radiation in this location as compared to other evaluated sunshine dependent models.

\subsubsection{Temperature Based Models for Makurdi}

The empirical temperature dependent models for Makurdi obtained through regression techniques based on Table 2 are

$$
\begin{gathered}
\frac{H}{H_{0}}=-0.0795+0.190 \ln \Delta T \\
\frac{H}{H_{0}}=0.163+0.111 \text { Sqrt } \Delta T \\
\frac{H}{H_{0}}=0.364+0.176 \frac{\Delta T}{S_{0}}
\end{gathered}
$$

The proposed developed empirical temperature dependent models for Makurdi obtained through regression techniques based on Table 3 are

$$
\begin{aligned}
& \frac{H}{H_{0}}=-1.73-0.236 \Delta T+0.00376(\Delta T)^{2}+1.85 \ln \Delta T \\
& \frac{H}{H_{0}}=-0.227+0.125 \Delta T-0.00480(\Delta T)^{2}+0.0 \exp \Delta T
\end{aligned}
$$

Table 6. Statistical analysis of the temperature dependent models for Makurdi.

\begin{tabular}{lllllll}
\hline Models & $\mathbf{R}^{2}$ & MBE & RMSE & MPE & t & NAE \\
\hline Eqn.21 (Chen) & 77.4 & 0.0112 & 1.0465 & -0.4204 & 0.0355 & 89.4385 \\
Eqn.22 (HS) & 74.0 & 0.0237 & 1.1265 & -0.5440 & 0.0697 & 87.7622 \\
Eqn.23 (Garcia) & 70.4 & 0.0071 & 1.2076 & -0.5198 & 0.0195 & 85.9357 \\
Proposed Models & $\mathrm{R}^{2}$ & MBE & RMSE & MPE & t & 96.6730 \\
Eqn.24 & 90.0 & -0.0093 & 0.7055 & -0.0192 & 0.0437 & NSE \\
Eqn.25 & 89.4 & -0.3849 & 1.0918 & 1.9187 & 95.1998 & 1.2493 \\
\hline
\end{tabular}

Table 7. Ranking of the evaluated temperature based models for Makurdi.

\begin{tabular}{llllllll}
\hline Models & $\mathbf{R}^{2}$ & MBE & RMSE & MPE & t & NSE & TA \\
\hline Eqn.21 (Chen) & 3 & 3 & 2 & 2 & 2 & 2 & 2 \\
Eqn.22 (HS) & 4 & 4 & 4 & 4 & 4 & 4 & 4 \\
Eqn.23 (Garcia) & 5 & 1 & 5 & 3 & 1 & 5 & 5 \\
\hline
\end{tabular}




\begin{tabular}{lllllllll}
\hline Models & $\mathbf{R}^{2}$ & MBE & RMSE & MPE & t & NSE & IA & Total Rank \\
\hline Proposed Models & $\mathrm{R}^{2}$ & MBE & RMSE & MPE & $\mathrm{t}$ & NSE & IA & Total Rank \\
Eqn.24 & 1 & 2 & 1 & 1 & 3 & 1 & 1 & 10 \\
Eqn.25 & 2 & 5 & 3 & 5 & 5 & 3 & 3 & 26 \\
\hline
\end{tabular}

Tables 6 and 7 summarizes the different statistical validation indicators utilized in this study and the ranking of the temperature dependent models for Makurdi. Based on the $\mathrm{R}^{2}$, NSE and IA the proposed model, equation 24 (quadratic logarithmic) has the highest values with $90.0 \%, 95.1998 \%$ and 98.7865\% respectively; the model also have the lowest RMSE and MPE values of $0.7055 \mathrm{MJm}^{-2} \mathrm{day}^{-1}$ and underestimation of $0.0192 \%$ in the estimated value. The Garcia model has the lowest MBE and t-test values with overestimation of 0.0071 $\mathrm{MJm}^{-2} \mathrm{day}^{-1}$ in its estimated value and 0.0195 respectively. The result of the temperature dependent models for Makurdi show that regardless of the overestimation and underestimation exhibited in their estimated values they are all within the acceptable range $(M P E \leq \pm 10 \%)$. Similarly, the calculated ttest values are less than the critical t-test values for all the examined models; therefore the t-test analysis shows that all the studied models are significant at $95 \%$ and $99 \%$ confidence levels.

The total ranks acquired by the various sunshine dependent models (Table 7) were in the range 10 to 28 . The overall results for Makurdi; revealed that the proposed quadratic logarithmic temperature dependent model given in equation 24 was found more accurate for estimating global solar radiation in this location as compared to other evaluated temperature dependent models.

\subsubsection{Sunshine Based Models for Ibadan}

The empirical sunshine dependent models for Ibadan obtained through regression techniques based on Table 1 are

$$
\begin{gathered}
\frac{H}{H_{0}}=0.184+0.690 \frac{S}{S_{0}} \\
\frac{H}{H_{0}}=0.0679+1.31 \frac{S}{S_{0}}-0.777\left(\frac{S}{S_{0}}\right)^{2} \\
\frac{H}{H_{0}}=0.515-2.27 \frac{S}{S_{0}}+8.26\left(\frac{S}{S_{0}}\right)^{2}-7.27\left(\frac{S}{S_{0}}\right)^{3} \\
\frac{H}{H_{0}}=0.617+0.124 \frac{S}{S_{0}}+0.216 \ln \left(\frac{S}{S_{0}}\right) \\
\frac{H}{H_{0}}=0.711+0.263 \ln \left(\frac{S}{S_{0}}\right) \\
\frac{H}{H_{0}}=-0.226+0.457 \exp \left(\frac{S}{S_{0}}\right) \\
\frac{H}{H_{0}}=0.183+0.789 \frac{S}{S n h} \\
\frac{H}{H_{0}}=0.798\left(\frac{S}{S_{0}}\right)^{0.593}
\end{gathered}
$$

\begin{tabular}{|c|c|c|c|c|c|c|c|c|}
\hline Models & $\mathbf{R}^{2}$ & MBE & RMSE & MPE & $\mathbf{t}$ & NSE & IA & Total Rank \\
\hline Eqn.26 & 5 & 7 & 8 & 9 & 7 & 7 & 7 & 50 \\
\hline Eqn.27 & 2 & 9 & 3 & 5 & 9 & 3 & 3 & 34 \\
\hline Eqn.28 & 1 & 8 & 1 & 7 & 8 & 1 & 1 & 27 \\
\hline Eqn.29 & 3 & 5 & 4 & 6 & 5 & 4 & 4 & 31 \\
\hline Eqn.30 & 4 & 4 & 5 & 1 & 4 & 5 & 5 & 28 \\
\hline Eqn.31 & 2 & 1 & 2 & 4 & 1 & 2 & 2 & 14 \\
\hline Eqn.32 & 6 & 3 & 9 & 8 & 2 & 2 & 9 & 39 \\
\hline Eqn.34 & 1 & 2 & 6 & 3 & 3 & 6 & 6 & 27 \\
\hline
\end{tabular}

Table 8. Statistical analysis of the sunshine dependent models for Ibadan.

\begin{tabular}{lllllll}
\hline Models & $\mathbf{R}^{\mathbf{2}}$ & MBE & RMSE & MPE & t & NSE \\
\hline Eqn.26 & 93.8 & 0.0212 & 0.6533 & -0.3157 & 0.1077 & 94.1623 \\
Eqn.27 & 94.9 & -0.0381 & 0.6012 & 0.1186 & 0.2108 & 98.4561 \\
Eqn.28 & 95.5 & 0.0318 & 0.5654 & -0.2601 & 0.1868 & 98.0574 \\
Eqn.29 & 94.7 & 0.0122 & 0.6123 & -0.188 & 0.0658 & 95.6278 \\
Eqn.30 & 94.6 & -0.0106 & 0.6163 & -0.0393 & 0.0571 & 94.8718 \\
Eqn.31 & 94.9 & 0.0031 & 0.5975 & -0.1101 & 0.0174 & 94.8058 \\
Eqn.32 & 92.5 & 0.006 & 0.7126 & -0.2831 & 0.028 & 95.1177 \\
Eqn.33 & 93.8 & -0.0186 & 0.6534 & -0.0801 & 0.0944 & 95.1177 \\
Eqn.34 & 95.5 & -0.0057 & 0.6184 & -0.0975 & 0.0305 & 94.1606 \\
\hline
\end{tabular}

Table 9. Ranking of the evaluated sunshine based models for Ibadan.

Tables 8 and 9 summarizes the different statistical validation indicators utilized in this study and the ranking of the sunshine dependent models for Ibadan. Based on the $\mathrm{R}^{2}$ the model, equation 28 (cubic) and 34 (exponent) sunshine dependent model has the highest value of $95.5 \%$. The model equation 28 (cubic) has the highest values of NSE and IA with $95.6278 \%$ and $98.8901 \%$ respectively; the model also has the lowest RMSE value of $0.5654 \mathrm{MJm}^{-2} \mathrm{day}^{-1}$. The model equation 31 (linear exponential) has the lowest MBE and t-test values with overestimation of $0.0031 \mathrm{MJm}^{-2} \mathrm{day}^{-1}$ in the estimated value and 0.0174 respectively. The model equation 30 (logarithmic) has the lowest MPE value with underestimation of $0.0393 \%$ in the 
estimated value. The result of the sunshine dependent models for Ibadan show that regardless of the overestimation and underestimation exhibited in their estimated values they are all within the acceptable range ( $M P E \leq \pm 10 \%)$. Similarly, the calculated t-test values are less than the critical t-test values for all the examined models; therefore the t-test analysis shows that all the studied models are significant at $95 \%$ and $99 \%$ confidence levels.

The total ranks acquired by the various sunshine dependent models (Table 9) were in the range 14 to 50. The overall results for Ibadan; revealed that the linear exponential sunshine dependent model given in equation 31 as proposed by Bakirci [28] was found more accurate for estimating global solar radiation in this location as compared to other evaluated sunshine dependent models.

\subsubsection{Temperature Based Models for Ibadan}

The empirical temperature dependent models for Ibadan obtained through regression techniques based on Table 2 are

$$
\begin{gathered}
\frac{H}{H_{0}}=-0.324+0.372 \ln \Delta T \\
\frac{H}{H_{0}}=-0.264+0.251 \text { Sqrt } \Delta T \\
\frac{H}{H_{0}}=0.144+0.455 \frac{\Delta T}{S_{0}}
\end{gathered}
$$

The proposed developed empirical temperature dependent models for Ibadan obtained through regression techniques based on Table 3 are

$$
\begin{gathered}
\frac{H}{H_{0}}=-0.55+0.39 \Delta T+0.0165(\Delta T)^{2}-0.502 .43 \ln \Delta T \\
\frac{H}{H_{0}}=-0.855+0.268 \Delta T-0.0128(\Delta T)^{2}-0.00000005 \exp \Delta T
\end{gathered}
$$

\begin{tabular}{|c|c|c|c|c|c|c|c|c|}
\hline Models & $\mathbf{R}^{2}$ & MBE & RMSE & MPE & $t$ & NSE & IA & Total Rank \\
\hline Eqn.35 (Chen) & 2 & 3 & 3 & 3 & 3 & 3 & 3 & 20 \\
\hline Eqn.36 (HS) & 3 & 2 & 4 & 1 & 2 & 4 & 4 & 20 \\
\hline Eqn.37 (Garcia) & 4 & 1 & 5 & 4 & 1 & 5 & 5 & 25 \\
\hline Proposed Models & $\mathrm{R}^{2}$ & MBE & RMSE & MPE & $\mathrm{t}$ & NSE & IA & Total Rank \\
\hline Eqn. 38 & 1 & 5 & 2 & 5 & 5 & 2 & 2 & 22 \\
\hline Eqn.39 & 1 & 4 & 1 & 2 & 4 & 1 & 1 & 14 \\
\hline
\end{tabular}

Table 10. Statistical analysis of the temperature dependent models for Ibadan.

\begin{tabular}{llllllll}
\hline Models & $\mathbf{R}^{\mathbf{2}}$ & MBE & RMSE & MPE & t & NSE \\
\hline Eqn.35 (Chen) & 83.0 & 0.0371 & 1.0599 & -0.6573 & 0.1161 & 84.6358 \\
Eqn.36 (HS) & 81.0 & -0.0128 & 1.1214 & -0.4252 & 0.038 & 82.8007 \\
Eqn.37 (Garcia) & 77.4 & 0.0061 & 1.2340 & -0.6911 & 0.0165 & 79.1726 \\
Proposed Models & $\mathrm{R}^{2}$ & MBE & RMSE & MPE & t & 95.11 \\
Eqn.38 & 91.2 & 0.2454 & 0.8227 & -1.584 & 1.0364 & NSE \\
Eqn.39 & 91.2 & 0.0782 & 0.7864 & -0.575 & 90.7426 & 9.3313 & 91.543 \\
\hline
\end{tabular}

Table 11. Ranking of the evaluated temperature based models for Ibadan.

Tables 10 and 11 summarizes the different statistical validation indicators utilized in this study and the ranking of the temperature dependent models for Ibadan. Based on the $\mathrm{R}^{2}$ the proposed models equation 38 (quadratic logarithmic) and 39 (quadratic exponential) has the highest value of $91.2 \%$. The proposed model equation 39 (quadratic exponential) has the lowest value of RMSE and highest values of NSE and IA with $0.7864 \mathrm{MJm}^{-2} \mathrm{day}^{-1}, 91.5430 \%$ and $97.8670 \%$ respectively. The Garcia model has the lowest MBE and t-test values with overestimation of $0.0061 \mathrm{MJm}^{-}$ ${ }^{2} \mathrm{day}^{-1}$ in the estimated value and 0.0165 respectively. The Hargreaves and Samani (HS) model has the lowest MPE value with underestimation of $0.4252 \%$ in the estimated value. The result of the temperature dependent models for Ibadan show that regardless of the overestimation and underestimation exhibited in their estimated values they are all within the acceptable range (MPE $\leq \pm 10 \%)$. Similarly, the calculated t-test values are less than the critical t-test values for all the examined models; therefore the t-test analysis shows that all the studied models are significant at
95\% and 99\% confidence levels.

The total ranks acquired by the various sunshine dependent models (Table 11) were in the range 14 to 25 . The overall results for Ibadan; revealed that the proposed quadratic exponential temperature dependent model given in equation 39 was found more accurate for estimating global solar radiation in this location as compared to other evaluated temperature dependent models.

The Hargreaves and Samani model results obtained for Ibadan in this study were compared to that carried out by Sanusi and Abisoye [36]. The model equation with its empirical constants is given in equation 36 while the empirical constants "a" and "b" given by Sanusi and Abisoye [36] are 0.278 and 0.331. In this study, the MBE, RMSE, MPE and $\mathrm{R}^{2}$ are found to be $-0.0128 \mathrm{MJm}^{-2}$ day $^{-1}, 1.1214$ $\mathrm{MJm}^{-2} \mathrm{day}^{-1},-0.4252 \%$ and $81.0 \%$ respectively while the MBE, RMSE, MPE and $\mathrm{R}^{2}$ given by Sanusi and Abisoye [36] are $0.82 \mathrm{MJm}^{-2}$ day $^{-1}, 1.59 \mathrm{MJm}^{-2}$ day $^{-1},-7.36 \%$ and $72.0 \%$ respectively. Thus, this is evident that the evaluated Hargreaves and Samani (HS) temperature dependent model 
in this study performs better as compared to those given by Sanusi and Abisoye [36]. However, the proposed quadratic exponential temperature dependent model given in equation
39 is reported as the best and therefore most suitable for estimating global solar radiation in this location as compared to other evaluated temperature dependent models.

\subsection{Comparison Betaween the Most Accurate Sunshine and Temperature Dependent Models}

\subsubsection{For Makurdi}

Table 12. Ranking of the most accurate sunshine and temperature dependent models for Makurdi.

\begin{tabular}{llllllll}
\hline Models & $\mathbf{R}^{2}$ & MBE & RMSE & MPE & t & NSE & TA \\
\hline Eqn. 20 & 1 & 1 & 1 & 2 & 1 & 1 & 1 \\
Eqn.24 & 2 & 2 & 2 & 1 & 2 & 2 & 2 \\
\hline
\end{tabular}

\subsubsection{For Ibadan}

Table 13. Ranking of the most accurate sunshine and temperature dependent models for Ibadan.

\begin{tabular}{llllllll}
\hline Models & $\mathbf{R}^{2}$ & MBE & RMSE & MPE & t & NSE & TA \\
\hline Eqn.31 & 1 & 1 & 1 & 1 & 1 & 1 & 1 \\
Eqn.39 & 2 & 2 & 2 & 2 & 2 & 2 & 2 \\
\hline
\end{tabular}

The result shown in Tables 12 and 13 shows that the sunshine dependent model (Eqn. 20 and 31) performed better than the temperature dependent model (Eqn. 24 and 39) in Makurdi and Ibadan respectively. This indicates that the sunshine dependent model is more accurate for estimating global solar radiation in the Guinea savannah climatic zone of Nigeria and this is in line with the study reported by Ogolo [7].

\subsection{Correlation Between the Measured and Estimated Sunshine and Temperature Dependent Models}

Figure $2 \mathrm{a}$ shows the comparison between measured and estimated sunshine dependent global solar radiation models for Makurdi. The estimated sunshine dependent models underestimated the measured global solar radiation in the month from January to March and in July and overestimated the measured in the month April, May and August. The pattern of variation of the estimated models follows the same pattern as that of the measured global solar radiation except that the measured global solar radiation decreases from March to April during the onset of the rainy season and then to August (short dry period) while the estimated models increases from March to April and decreases subsequently to July and increases further to

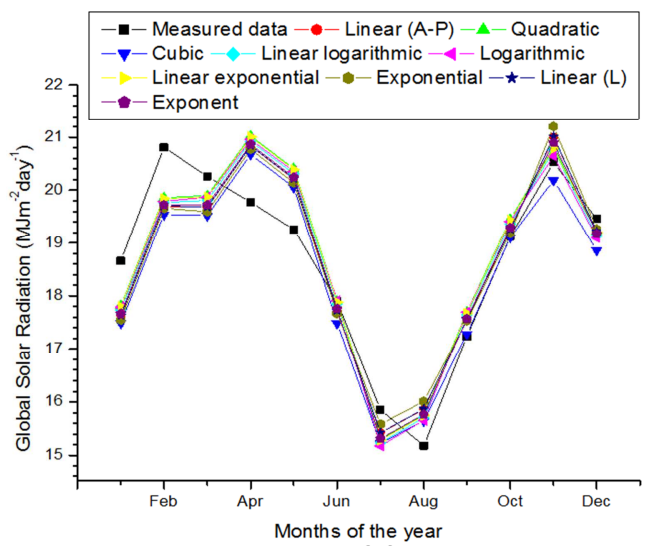

(a)
November during the onset of dry season and drop to December. The measured global solar radiation increases from August to November and drop to December. The third order Ångström type cubic model show a slight underestimation of its estimated values in the month of June, November and December as compared to other measured and estimated sunshine dependent models.

Figure $2 \mathrm{~b}$ shows the comparison between measured and estimated temperature dependent global solar radiation models for Makurdi. The estimated temperature dependent models underestimated the measured global solar radiation in the month of August and September and overestimated the measured in the month of May, June, October and November. The temperature dependent models almost behaved differently especially the existing models (Chen, HS and Garcia). It was observed that while the measured and proposed temperature dependent models exhibit a downward trough in August, the existing models delayed until October; this is line with the study reported by Ogolo [7] for Lokoja located in the Guinea savannah climatic region. The proposed temperature dependent models show better fitting with the measured data while the model, equation 24 displayed the best fitting for Makurdi.

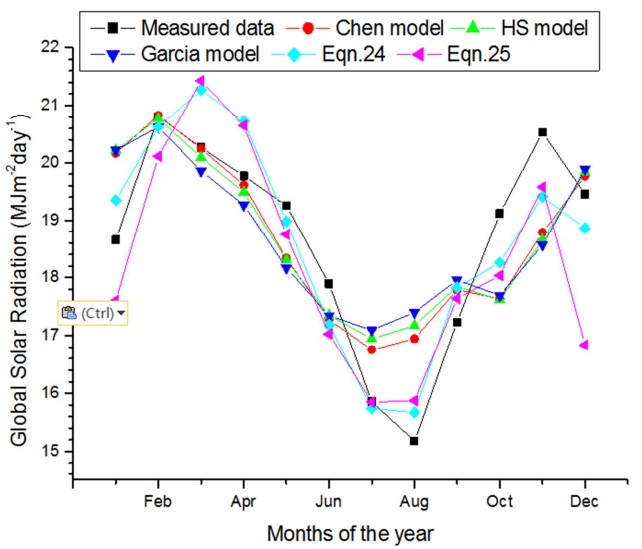

(b)

Figure 2. Comparison between measured and estimated global solar radiation for Makurdi (a) Sunshine dependent models (b) temperature dependent models. Eqn.24-Quadratic logarithmic, Eqn.25-Quadratic exponential. 
Figure $3 \mathrm{a}$ shows the comparison between measured and estimated sunshine dependent global solar radiation models for Ibadan. The estimated sunshine dependent models underestimated the measured global solar radiation in the month from May, August, September and December and overestimated the measured in the month from January to March and in June. The pattern of variation of the estimated models follows the same pattern as that of the measured global solar radiation except that the measured global solar radiation decreases from February to May while the estimated models increases from February to May. The third order Ångström type cubic model show a slight overestimation of its estimated values in the month of April and May when compared to the measured and estimated sunshine dependent models.

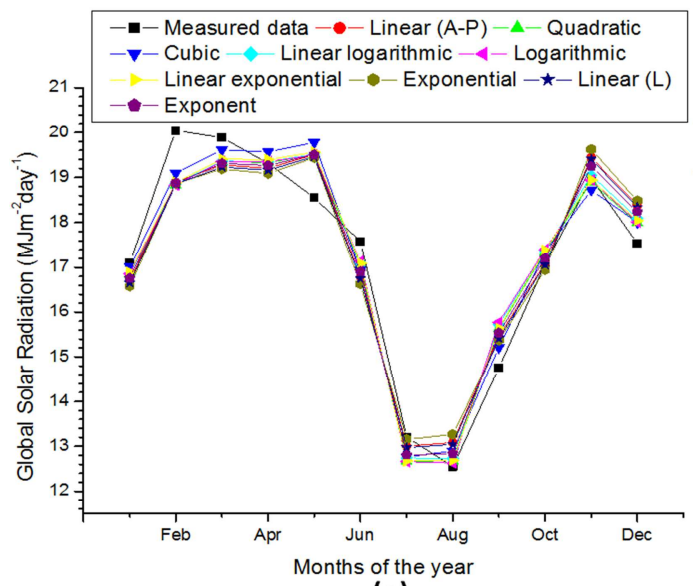

(a)
Figure $3 \mathrm{~b}$ shows the comparison between measured and estimated temperature dependent global solar radiation models for Ibadan. The estimated temperature dependent models underestimated the measured global solar radiation in the month of June and November and overestimated the measured in the month January, March, August and September. The Garcia model underestimated the measured and other estimated temperature dependent models in the months from April to June. Similarly, is the HS model in the months from October to December. The existing models (Chen, HS and Garcia) overestimated the measured and other estimated temperature dependent models in the month of January. Similarly, are the models equation 38 and 39 in the month of April and May.

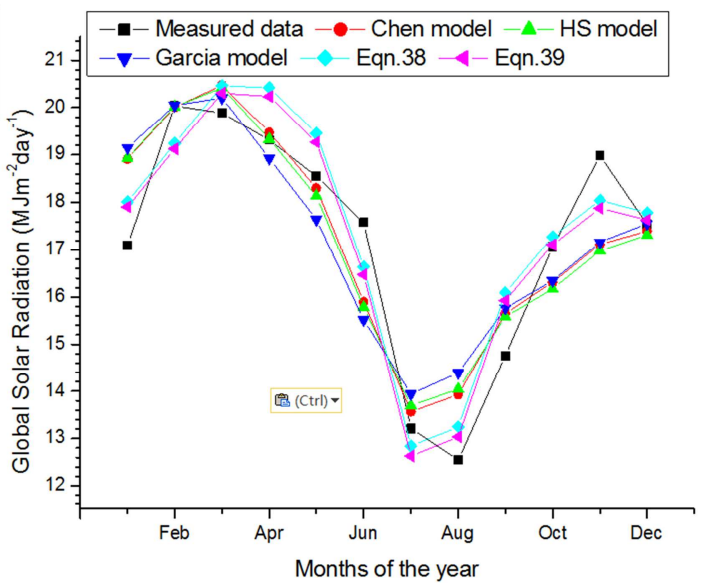

(b)

Figure 3. Comparison between measured and estimated global solar radiation for Ibadan (a) sunshine dependent models (b) temperature dependent models. Eqn.38-Quadratic logarithmic, Eqn.39-Quadratic exponential.

\section{Conclusion}

The performances of both sunshine and temperature dependent models for global solar radiation estimation over Makurdi and Ibadan situated in the Guinea savannah climatic zone of Nigeria were evaluated using monthly average daily global solar radiation, sunshine hours, maximum and minimum temperature meteorological data during the period of thirty one (1980-2010) years. In this study, nine (9) different existing sunshine dependent models were compared. The proposed quadratic logarithmic and quadratic exponential temperature dependent models were compared to three existing temperature dependent models (Chen, HS and Garcia). The evaluated models are validated using seven different statistical indicators of coefficient of determination $\left(\mathrm{R}^{2}\right)$, Mean Bias Error (MBE), Root Mean Square Error (RMSE), Mean Percentage Error (MPE), t-test, NashSutcliffe Equation (NSE) and Index of Agreement (IA) to determine the most accurate model in each of the studied locations. The most suitable sunshine and temperature dependent models were compared in each location. The results of this study showed that:

(i) The exponent sunshine dependent model proposed by Bakirci and the linear exponential sunshine dependent model proposed by Bakirci were found more accurate for estimating global solar radiation in Makurdi and Ibadan respectively.

(ii) The proposed quadratic logarithmic and quadratic exponential temperature dependent models were found more suitable for estimating global solar radiation in Makurdi and Ibadan respectively.

(iii) The models recommended in this study can be applied in locations with similar weather condition.

(iv) The variation of the observed regression coefficients for the nine sunshine and five temperature dependent models revealed that they are site-specific and therefore the empirical coefficient need to be calibrated against the local data when applied in locations other than where the model was developed regardless of similarity in climatic zone.

(v) The result of this study show that the performance of each model varies significantly in each of the locations under investigation.

(vi) The sunshine dependent models was found more suitable for estimating global solar radiation in the Guinea savannah climatic zone of Nigeria when compared to the temperature dependent models and has been revealed from the figures comparing the measured and estimated models as the sunshine dependent models depicts the best fitting with the measured global solar radiation data. 


\section{Acknowledgements}

The authors are grateful to the management and staff of the Nigerian Meteorological Agency (NIMET), Oshodi, Lagos for providing all the necessary data used in this present study. The contribution and suggestions of the anonymous reviewers is well appreciated.

\section{References}

[1] Alam, M., Saha, S., Chowdhury, M and Rahman, M. (2005). Simulation of Solar Radiation System, Am. J. Appl. Sci., 2 (4), 751-758.

[2] Al-Salihi, A., Kadum, $M$ and Mohammed, A. (2010). Estimation of Global Solar Radiation on Horizontal Surface Using Meteorological Measurement for different Cities in Iraq, Asian J. Sci. Res., 3 (4), 240-248.

[3] G. A. Baigorria, E. B. Villegas, I. Trebejo, J. F. Carlos, and R. Quiroz, "Atmospheric transmissivity: distribution and empirical estimation around the central Andes," International Journalof Climatology, vol. 24, no. 9, pp. 1121-1136, 2004.

[4] Iziomon, M. G and Mayer, H. (2002). Assessment of some global solar radiation parameterizations. Journal of Atmospheric and Solar-Terrestrial Physics, vol. 64, no. 15, pp. 1631-1643.

[5] Li, H., Ma, W., Lian, Y., Wang, X and Zhao, L. (2011). "Global solar radiation estimation with sunshine duration in Tibet, China," Renewable Energy, vol.36, no. 11, pp. 31413145 .

[6] Rivington, M. Bellocchi, G., Matthews, K. B and Buchan, K. (2005). Evaluation of three model estimations of solar radiation at 24 UK stations," Agricultural and Forest Meteorology, vol. 132, no. 3-4, pp. 228-243.

[7] Ogolo, E. O. (2010). Evaluating the performance of some predictive models for estimating global solar radiation across varying climatic conditions in Nigeria. Indian Journal of Radio \& space Physics, 39, 121-131.

[8] Rahimikhoob, A. (2010). Estimating global solar radiation using artificial neural network and air temperature data in a semi-arid environment," Renewable Energy, vol. 35, no. 9, pp. 2131-2135.

[9] Abraha, M. G and Savage, M. J. (2008). Comparison of estimates of daily solar radiation from air temperature range for application in crop simulations," Agricultural and Forest Meteorology, vol. 148, no. 3, pp. 401-416.

[10] Huashan, L., Fei, C., Xianlong, W and Weibin, M. (2014). A Temperature-Based Model for Estimating Monthly Average Daily Global Solar Radiation in China. Hindawi Publishing Corporation. The Scientific World Journal, Volume 2014 1-9. http://dx.doi.org/10.1155/2014/128754.

[11] Ångström, A. (1924). Solar and terrestrial radiation. Quarterly Journal of the Royal Meteorological society, 50, 121-125.

[12] Page, J. K. (1964). The estimation of monthly mean values of daily total short-wave radiation on vertical and inclined surfaces from sunshine records for latitude $40^{\circ} \mathrm{N}-40^{\circ} \mathrm{S}$. Proceeding of the UN Conference on New Sources of Energy, Rome, 4, 378-390.
[13] El-Sebaii, A and Trabea, A. (2005). Estimation of Global Solar Radiation on Horizontal Surfaces Over Egypt, Egypt. J. Solids, 28, 1, 163-175.

[14] Isikwue, B. C., Amah, A. N and Agada, P. O. (2012). Empirical Model for the Estimation of Global Solar Radiation in Makurdi, Nigeria, Global Journal of Science Frontier Research Physics \& Space Science., 12 (1).

[15] Gadiwala, M. S., Usman, A., Akhtar, M and Jamil, K. (2013). Empirical Models for the Estimation of Global Solar Radiation with Sunshine Hours on Horizontal Surface in Various Cities of Pakistan, Pakistan Journal of Meteorology., 9 (18), 43-49.

[16] Olatona, G. I and Adeleke, A. E. (2015). Estimation of Solar Radiation over Ibadan from Routine Meteorological Parameters, The International Journal Of Engineering And Science (IJES)., 4 (3), 44-51.

[17] WMO, A Note on Climatological Normal. Technical Note. World Meteorological Organization, Geneva, Switzerland. (1967).

[18] Ojo, O. S and Adeyemi, B. (2014). Estimation of Solar Radiation using Air Temperature and Geographical Coordinate over Nigeria, The Pacific Journal of Science and Technology, 15, 2, 78-88.

[19] Olaniran, O. J. (1983). The Monsoon factor and the seasonality of rainfall distribution In Nigeria, Malaysian $J$ Trop Geog, 7 pp 38-45.

[20] Iqbal, M. (1983). An introduction to solar radiation, first ed. Academic Press, New York.

[21] Zekai, S. (2008). Solar energy fundamentals and modeling techniques: atmosphere, Environment, climate change and renewable energy, first ed. Springer, London.

[22] Falayi, E. O., Rabiu, A. B and Teliat, R. O. (2011). Correlations to estimate monthly mean of daily diffuse solar radiation in some selected cities in Nigeria, Pelagia Research Library, 2, 4, 480-490.

[23] Prescott, J. A. (1940). Transactions of the Royal Society of Australia 48, 114-8.

[24] Ogelman, H., Ecevit, A and Tasdemiroglu, E. (1984). A new method for estimating solar radiation from bright sunshine data, Solar Energy, 33, 619-25.

[25] Samuel, T. D. M. A. (1991). Estimation of global radiation for Sri Lanka, Solar Energy, 47, 333-337.

[26] Newland, F. J. (1988). A study of solar radiation models for the coastal regions of South China, Solar Energy, 31 227-235.

[27] Ampratwum, D. B and Dorvlo, A. S. S. (1999). Estimation of solar radiation from the number sunshine hours, Applied Energy, 63 161-167.

[28] Bakirci, K. (2009). Correlations for estimation of daily global solar radiation with hours of bright sunshine in Turkey, Energy, 34, 485-501.

[29] Almorox, J and Hontoria, C. (2004). Global solar radiation estimation using sunshine duration in Spain, Energy Conversion and Management, 45, 1529-1535.

[30] Louche, A., Notton, G., Poggi, P and Simonnot, G. (1991). Correlations for direct and Global horizontal irradiation on a French Mediterranean site, Solar Energy, 46, 261-6. 
[31] Chen, R., Ersi, K., Yang, J., Lu, Sand Zhao, W. (2004). Validation of five global radiation Models with measured daily data in China. Energy Conversion and Management, 45, 1759-1769.

[32] Hargreaves, G. and Samani, Z. (1982). Estimating potential evapotranspiration. Journal of Irrigation and Drainage Engineering. ASCE, 108 225-230.

[33] Garcia, J. V. (1994). PrincipiosF'isicos de la Climatolog'ia. Ediciones UNALM (Universidad Nacional Agraria La Molina: Lima, Peru).
[34] Bevington, P. R. (1969). Data reduction and error analysis for the physical sciences, first ed. McGraw Hill Book Co., New York.

[35] Merges, H. O., Ertekin, C and Sonmete, M. H. (2006). Evaluation of global solar radiation Models for Konya, Turkey. Energy Conversion and Management, 47, 3149-3173.

[36] Sanusi, Y. K and Abisoye, S. G. (2011). Estimation of Solar Radiation at Ibadan, Nigeria, Journal of Emerging Trends in Engineering and Applied Sciences (JETEAS), 2 (4), 701-705. 